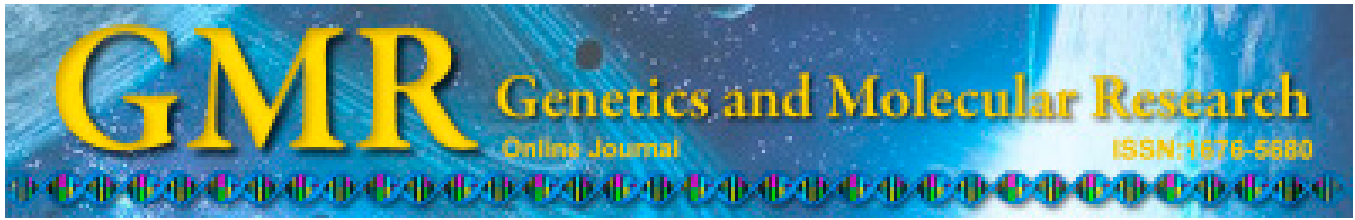

\title{
Application of vacuum-assisted closure in seawater-immersed wound treatment under different negative pressures
}

\author{
L. Cao, M.M. Peng, J.J. Sun, X.C. Yu and B. Shi \\ Department of Plastic Surgery, \\ The Chinese People's Liberation Army General Staff Hospital, Beijing, \\ Beijing, China
}

Corresponding author: B. Shi

E-mail: shibingbeijing@126.com

Genet. Mol. Res. 14 (2): 6146-6155 (2015)

Received July 22, 2014

Accepted October 30, 2014

Published June 8, 2015

DOI http://dx.doi.org/10.4238/2015.June.8.12

\begin{abstract}
The therapeutic effect of vacuum-assisted closure (VAC) has been confirmed in many types of complex wounds, but there are few relevant reports regarding seawater-immersed wounds. The aim of this study was to determine the effect of VAC on seawater-immersed wound healing under different negative pressures and explore the optimal negative pressure value. Four purebred miniature pigs were used as the experimental animal models. Four acute, symmetrical wounds were made on each side of the spine and designated as the experimental group (wounds with $2 \mathrm{~h}$ of seawater immersion) and the control group (wounds without seawater immersion). Wounds were divided into a conventional dressing group and 3 further groups with different VAC therapies (negative pressure at either 120, 180, or 240 $\mathrm{mmHg}$ ). The extent of wound healing, and speed of granulation growth and re-epithelialization were measured. Bacterial flora distribution in the wounds was observed, and fibronectin levels in the exudate of the wounds were tested. Results showed that seawater immersion aggravated
\end{abstract}


wound injury and that VAC therapy with $180 \mathrm{mmHg}$ negative pressure induced the fastest epidermis migration, obvious edema elimination, significant capillary proliferation, and the highest level of fibronectin, and that in wounds, the proportion of Gram-negative bacteria tended to decrease and that of Gram-positive bacteria tended to increase. Our results show that VAC promotes seawater-immersed wound healing and that $180 \mathrm{mmHg}$ negative pressure may be optimal for wound healing.

Key words: Vacuum-assisted closure; Wound therapy; Seawater immersion; Negative pressure

\section{INTRODUCTION}

A seawater-immersed wound is more complex, changes more rapidly, and heals more difficultly compared with an ordinary wound. Moreover, subsequent hypothermia, systemic infection, metabolic abnormalities, and decreased resistance may delay or even prevent healing (Hu et al., 2010; Byard et al., 2011; Dahl, 2011). Thus, vacuum-assisted closure (VAC) technology was proposed as a new therapy for wound healing, and its application was first reported by the German Dr. Fleischmann (Li et al., 2013). In recent years this technique has experienced rapid development and has been widely used to treat various acute and chronic wounds with excellent outcomes (Gabriel et al., 2009; Witkowski et al., 2009; Palm et al., 2011; Wood and Molnar, 2011; Masden et al., 2012; Ogawa, 2012). Both locally and abroad, the VAC mechanism has attracted a great deal of research, and results show that VAC plays various roles in wound healing: cleaning of wound exudate, reduction of peripheral edema, improvement of local blood supply, removal of bacteria, inhibition of bacterial proliferation, acceleration of granulation growth, and re-epithelialization (Sexena et al., 2004; Labler et al., 2006; Mouës et al., 2008; Chan, 2009; Parker, 2012; Chen et al., 2013; Dong et al., 2013). Thus, this technique can shorten wound healing time and provide a bed for delayed skin grafts. Recent studies have found that VAC improve the survival rate of transplanted skin and flaps (Scherer et al., 2002; Gupta, 2012), and it has also been applied to the clinical surgical suture (Grauhan et al., 2013). Therefore, it is hypothesized that VAC technology may become an effective treatment for seawater-immersed wounds.

In our country, pressure values usually range from 120 to $125 \mathrm{mmHg}$, as this value is conducive to granulation growth (Mouës et al., 2008). However, there have been reports regarding the application of higher negative pressures $(450-600 \mathrm{mmHg}$ ) (Morykwas et al., 2001). Timmers et al. (2005) believe that the negative pressure should be selected according to the density of the wound tissue - for dense tissue, a relatively higher negative pressure (300$400 \mathrm{mmHg}$ ) should be selected, while for loose tissue, a lower negative pressure (125-130 $\mathrm{mmHg}$ ) is more suited. There are currently no reports regarding VAC treatment for seawaterimmersed wounds.

In the present study, seawater-immersed wound healing, bacterial growth, histopathology, and fibronectin (FN) were investigated under different negative pressures with the aim of obtaining the ideal negative pressure value for application in VAC therapy. This study further explored new treatments for seawater-immersed wounds and provides experimental evidence for the corresponding mechanism of action. 


\section{MATERIAL AND METHODS}

\section{Experimental animals and groups}

Four purebred miniature pigs - males and females - with an average weight of 40 $\mathrm{kg}$ were used for this study (Experimental Animal Center of Dalian Medical University, China). The back of each pig was divided into 2 sections with the spine regarded as the midline. The left side of the back was designated the experimental side (with seawater immersion group) and the right side was the control side (without seawater immersion group). Acute wounds were made symmetrically with 4 wounds in each group: a single wound received conventional dressing and the remaining 3 were allocated to the VAC treatment group with application of different negative pressures $(120,180$, and 240 $\mathrm{mmHg})$.

\section{Animal models}

One month before the study, pigs were numbered 1 to 4 and given normal access to water and food (animals were fed by single-column feeding). Twelve hours prior to the experimental procedure, access to drinking water was prohibited and animals received a compound, fast, new intramuscular anesthesia. After cleaning and skin preparation, 4 circular wounds were made ( $4 \mathrm{~cm}$ in diameter, $10-\mathrm{cm}$ intervals, and subcutaneous depths) (Figure 1), after which the animals were placed in the left lateral position and immersed in a basin of seawater $\left(10^{\circ} \mathrm{C}\right)$. Special care was taken to protect the wound on the right side and avoid contamination with seawater. Seawater was replaced every $10 \mathrm{~min}$ and maintained at a constant temperature for $2 \mathrm{~h}$. In the conventional dressing group, the wound was covered and fixed with saline gauze. In the VAC therapy group, wounds were completely covered with a $4 \mathrm{~cm}$ long medical sponge and sealed with transparent film and an elastic bandage. After reinforcement of this dressing, the wound was connected to continuous suction.
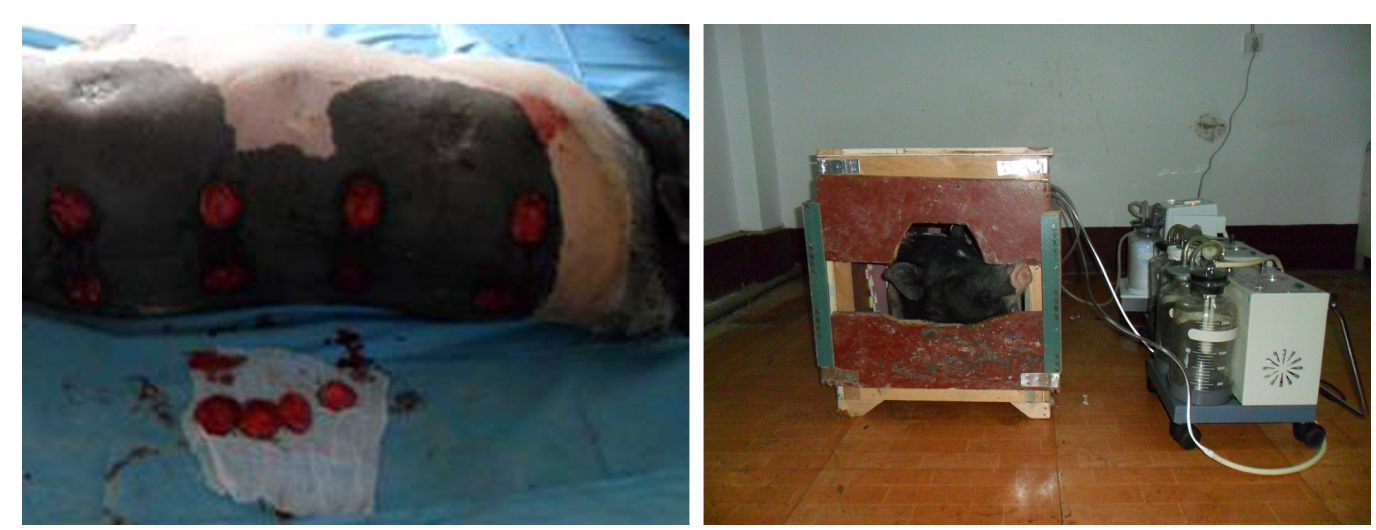

Figure 1. Wound design and connection to the negative pressure device. The seawater-immersed wounds were made in purebred miniature pigs, and vacuum-assisted closure was performed with different negative pressures. 


\section{Observation of general wound morphology}

At $1,3,5$, and 7 days after wound preparation, dressings were changed and the general morphology of the wounds was captured using macro-photography. Wound size, degree of swelling, basilar granulation growth, and epithelial progression at the wound edge were observed. After 7 days, VAC was removed and an ordinary dressing applied to the wounds. At 10,15 , and 20 days post-procedure, the wounds were reassessed.

At $1,3,5$, and 7 days after wound model preparation and VAV application, a disposable sterile throat swab was used to swab the center of the wound (within $2 \times 2 \mathrm{~cm}$ ) with a Z-shaped method, and the swab was reserved for agar culture of flora distribution and bacteriological qualitative detection.

\section{Immunohistochemistry}

At 1, 3, 5, and 7 days post-procedure, the closed dressings were removed and wounds were sealed with sterile disposable foil. One hour later, the closed foil was opened and $1 \mathrm{~mL}$ exudate was carefully absorbed. Exudate samples were immediately transferred to a sterile Voges-Proskauer tube and frozen at $-20^{\circ} \mathrm{C}$. For bacterial detection, all samples were thawed at room temperature, and stored in the refrigerator at a constant temperature of $2^{\circ}-8^{\circ} \mathrm{C}$ and removed the next day. Samples were centrifuged at $3000 \mathrm{rpm}$ for $20 \mathrm{~min}$, and the supernatant was collected for a double-antibody sandwich ELISA in order to evaluate FN levels.

\section{Statistical analysis}

The FN content of the wounds was reported as means \pm standard deviation (SD). Oneway analysis of variance and Student $t$-tests were performed to determine statistically significant differences among the experimental groups. A P value of less than 0.05 was considered to be significant.

\section{RESULTS}

\section{Effect of VAC on the general wound morphology}

One day after VAC therapy, significant differences in the morphology of wounds were observed between the control and experimental groups. As presented in Figure 2, in the experimental group, obvious swelling and opaque white edging was observed while the base of wound was maroon in color. Poor organizational activity of the wounds was observed in the experimental group. In the control group, less wound edge swelling was observed and both the edges and the base of the wound were pink in color. Good organizational activity was observed in the control group.

Three days after VAC treatment, wounds dried (the scab was thin and easy to peel) and bright red, fine granular organization began to appear in the callus tissue, which bled easily with touch. There was no significant difference in wound morphology between the 2 groups.

As presented in Figure 3, 7 days after VAC treatment the base of all wounds became pink in color and formed a smooth surface. As typical granulation tissue, wounds bled easily 
with touch. In the experimental group, peripheral swelling subsided and the epidermis of the wound edge exhibited forward migration. A negative pressure value of $180 \mathrm{mmHg}$ resulted in the fastest wound epidermis migration up to $6 \mathrm{~mm}$.

Seven days later the wounds gradually scabbed over. On the 15th day, healing was accelerated and by the 20th day, the base of the wound was essentially healed and only a small amount of scabbing was visible. In the experimental group, the residual wound scab was the smallest $(1.5 \times 1.8 \mathrm{~cm})$ with $180 \mathrm{mmHg}$ negative pressure. In the control group, the residual wound scab was the smallest $(1.6 \times 1.8 \mathrm{~cm})$ with $120 \mathrm{mmHg}$ negative pressure.
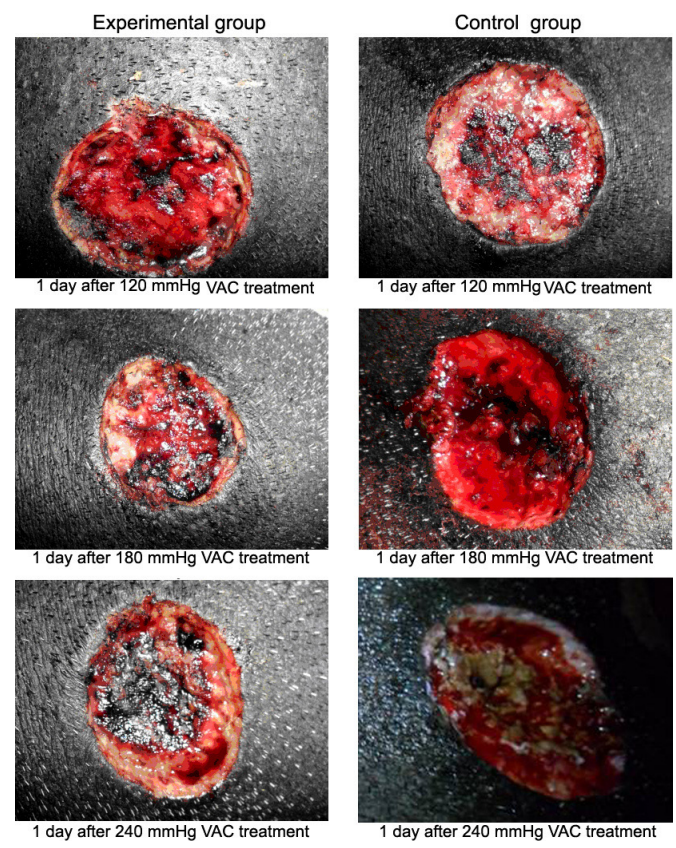

Figure 2. Effect of vacuum-assisted closure (VAC) on the general morphology of wounds 1 day after treatment. Seawater-immersed wounds were made in purebred miniature pigs, and VAC was performed with different negative pressures. The general morphology of wounds was observed.
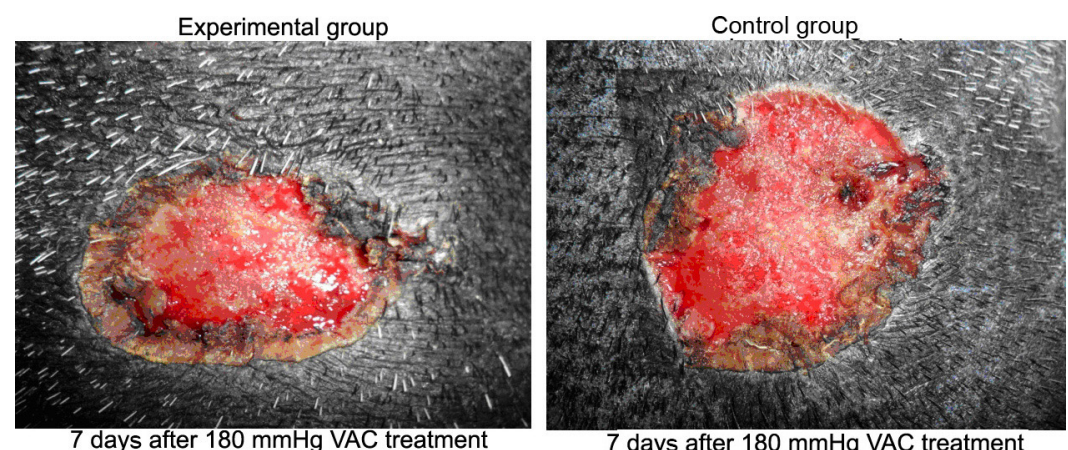

Figure 3. Effect of vacuum-assisted closure (VAC) on the general morphology of wounds 7 days after treatment. Seawater-immersed wounds were made in purebred miniature pigs, and VAC was performed with different negative pressures. The general morphology of wounds was observed. 


\section{Effect of VAC on the bacteriology of wounds}

As presented in Table 1, Gram-positive $\left(\mathrm{G}^{+}\right)$bacteria were predominantly seen in the experimental group. $\mathrm{G}^{+}$bacteria included Staphylococcus xylosus and Staphylococcus saccharolyticus, which belong to coagulase negative Staphylococcus and are generally considered to be non-pathogenic bacteria. Gram-negative $\left(\mathrm{G}^{-}\right)$bacteria occurred predominantly in the control group and included Pseudomonas alcaligenes and Pseudomonas aeruginosa. VAC treatment altered the redistribution of wound flora, and low distribution tends towards a low probability of bacterial infection.

Table 1. Main bacterial species distribution in the wounds.

\begin{tabular}{|c|c|c|c|}
\hline & After surgery (1 day) & After surgery (3 days) & After surgery (7 days) \\
\hline $\begin{array}{l}\text { Control + conventional } \\
\text { dressing group }\end{array}$ & (G) Pseudomonas aeruginosa & (G) Pseudomonas aeruginosa & (G) Pseudomonas aeruginosa \\
\hline $\begin{array}{l}\text { Control + } 120 \mathrm{mmHg} \\
\text { VAC group }\end{array}$ & (G) Pseudomonas aeruginosa & (G) Pseudomonas alcaligenes & (G) Pseudomonas alcaligenes \\
\hline $\begin{array}{l}\text { Control + } 180 \mathrm{mmHg} \\
\text { VAC group }\end{array}$ & (G) Pseudomonas alcaligenes & $\left(\mathrm{G}^{-}\right)$Pseudomonas aeruginosa; $\mathrm{G}^{+}$ & (G) Pseudomonas alcaligenes \\
\hline $\begin{array}{l}\text { Control }+240 \mathrm{mmHg} \\
\text { VAC group }\end{array}$ & (G) Pseudomonas alcaligenes & (G) Pseudomonas aeruginosa & (G) Pseudomonas aeruginosa; $\mathrm{G}^{+}$ \\
\hline $\begin{array}{l}\text { Experimental + conventional } \\
\text { dressing group }\end{array}$ & (G) Pseudomonas aeruginosa & (G) Pseudomonas aeruginosa & (G) Pseudomonas alcaligenes \\
\hline $\begin{array}{l}\text { Experimental + } 120 \mathrm{mmHg} \\
\text { VAC group }\end{array}$ & (G) Pseudomonas aeruginosa & (G) Pseudomonas aeruginosa & $\mathrm{G}^{+}$ \\
\hline $\begin{array}{l}\text { Experimental }+180 \mathrm{mmHg} \\
\text { VAC group }\end{array}$ & (G) Pseudomonas aeruginosa; $\mathrm{G}^{+}$ & $\mathrm{G}^{+}$ & $\left(\mathrm{G}^{-}\right)$Pseudomonas aeruginosa; $\mathrm{G}^{+}$ \\
\hline $\begin{array}{l}\text { Experimental + } 240 \mathrm{mmHg} \\
\text { VAC group }\end{array}$ & (G) Pseudomonas aeruginosa & & (G) Pseudomonas aeruginosa \\
\hline
\end{tabular}

Seawater-immersed wounds were made in purebred miniature pigs. Vacuum-assisted closure (VAC) was performed with different negative pressures, and bacterial flora distribution in the wounds were evaluated. $\mathrm{G}^{+}$: xylose sugar aureus staphylococcus \& solution.

\section{Effect of VAC on FN levels in wound exudate}

As presented in Table 2, the levels of FN in wound exudate increased over time in both the control and experimental groups.

Table 2. FN levels in the exudate of wounds $(\mu \mathrm{g} / \mathrm{L})$.

\begin{tabular}{|c|c|c|c|c|c|}
\hline & $\begin{array}{l}\text { After surgery } \\
\text { ( } 0 \text { day) }\end{array}$ & $\begin{array}{l}\text { After surgery } \\
\text { (1 day) }\end{array}$ & $\begin{array}{l}\text { After surgery } \\
\text { (3 days) }\end{array}$ & $\begin{array}{l}\text { After surgery } \\
\text { ( } 5 \text { days })\end{array}$ & $\begin{array}{l}\text { After surgery } \\
\text { (7 days) }\end{array}$ \\
\hline Control + conventional dressing group & $79.32 \pm 6.42$ & $76.54 \pm 5.89$ & $82.33 \pm 8.63$ & $85.46 \pm 7.45$ & $91.33 \pm 8.76$ \\
\hline Control + $120 \mathrm{mmHg}$ VAC group & $82.57 \pm 7.69$ & $80.74 \pm 6.81$ & $94.67 \pm 7.35^{*}$ & $98.31 \pm 8.11^{*}$ & $116.93 \pm 9.07 *$ \\
\hline Control + $180 \mathrm{mmHg}$ VAC group & $76.33 \pm 5.42$ & $79.16 \pm 8.07$ & $92.14 \pm 10.23^{*}$ & $96.44 \pm 8.71^{*}$ & $108.79 \pm 10.08 *$ \\
\hline Control $+240 \mathrm{mmHg}$ VAC group & $82.93 \pm 6.34$ & $86.73 \pm 8.14$ & $90.05 \pm 8.74$ & $95.41 \pm 8.92 *$ & $106.13 \pm 9.41^{*}$ \\
\hline Experimental + conventional dressing group & $76.31 \pm 8.66$ & $77.66 \pm 8.04$ & $79.42 \pm 7.31$ & $81.04 \pm 8.26$ & $81.77 \pm 7.29$ \\
\hline Experimental $+120 \mathrm{mmHg}$ VAC group & $81.78 \pm 7.18$ & $82.46 \pm 8.21$ & $87.69 \pm 7.38$ & $92.34 \pm 8.46^{\#}$ & $105.05 \pm 9.69^{\#}$ \\
\hline Experimental + $180 \mathrm{mmHg}$ VAC group & $78.31 \pm 7.14$ & $85.60 \pm 7.36$ & $90.03 \pm 7.54^{\#}$ & $96.42 \pm 8.67^{\#}$ & $110.52 \pm 9.28^{\#}$ \\
\hline Experimental $+240 \mathrm{mmHg}$ VAC group & $77.52 \pm 8.34$ & $78.67 \pm 7.27$ & $82.36 \pm 9.21$ & $89.45 \pm 8.31$ & $96.18 \pm 9.06^{\#}$ \\
\hline
\end{tabular}

Seawater-immersed wounds were made in purebred miniature pigs. Vacuum-assisted closure (VAC) was performed with different negative pressures. The level of fibronectin (FN) in the exudate of wounds was tested. Data are reported as the means $\pm \mathrm{SD}(\mathrm{N}=4) .{ }^{*} \mathrm{P}<0.05$, compared with the control + conventional dressing group; ${ }^{\#} \mathrm{P}<0.05$, compared with the experimental + conventional dressing group. 
Compared with the levels of FN in the control + conventional dressing group, the levels in wound exudate were significantly increased in the control $+120,180$, and $240 \mathrm{mmHg}$ VAC groups (all $\mathrm{P}<0.05$ ). VAC therapy with $120 \mathrm{mmHg}$ negative pressure had the most obvious effect. Compared with the levels of FN in the experimental + conventional dressing group, the levels in wound exudate were significantly increased in the experimental $+120,180$, and $240 \mathrm{mmHg}$ VAC groups (all $\mathrm{P}<0.05$ ). VAC therapy with $180 \mathrm{mmHg}$ negative pressure had the most obvious effect.

\section{DISCUSSION}

\section{Inflammatory response of a seawater-immersed wound may be ameliorated by VAC technology that improves local wound blood circulation and promotes granu- lation formation and wound healing}

After seawater immersion, infection of the wounds occurred earlier and was more potent, as seawater has a high alkaline, high sodium, and high potassium content. The following pathophysiological changes occur in wounds and result in increased local tissue necrosis (Dahl, 2011): increased serum electrolyte concentration, intracellular dehydration, congestion, edema, disordered microcirculation, and many micro-thromboses. Studies have shown that seawater immersion induces excessive inflammatory mediators (TNF- $\alpha$, IL-6, etc.) that trigger a severe inflammatory reaction and delay wound healing (Byard et al., 2011). In addition, seawater contains a large number of pathogens and resultant infection may impede wound healing by causing local hypoxia and extracellular matrix changes, aggravated tissue damage, and accelerated tissue degeneration and necrosis (Hu et al., 2010).

The present study found that 3 days after VAC therapy in the experimental group, the base of the wound exhibited fresh granulation tissue and the epidermis began to migrate. In the experimental group, 7 days after VAC therapy with $180 \mathrm{mmHg}$ negative pressure, migration was the fastest and typical mature granulation tissue had formed.

Research has confirmed that VAC may improve wound microcirculation and blood flow and expand capillaries. As an increased blood supply to the wound and improved local microcirculation occurred, exudate and necrosis liquids were cleared timeously and the bacterial content and resultant toxins in the wound were reduced in order to effectively control the infection (Gabriel et al., 2009; Wood and Molnar, 2011; Ogawa, 2012). The closed conditions of the wounds caused relative hypoxia and formed an acidic environment, which inhibited microbial growth, while the low-oxygen environment could simultaneously lead to autolyzed debridement (Wood and Molnar, 2011). Decreased oxygen tension prompted initiation of the repair signal, release of fibrinolytic activator enzymes, and more rapid dissolution of fibrin, and promoted wound healing.

The animal experiment confirmed that seawater immersion impacts angiogenesisrelated genes and inhibits angiogenesis (Yan et al., 2005). Vascular endothelial cells are involved in the entire process of angiogenesis and are important repair cells. Negative pressuregenerated mechanical stress can promote such repair cell proliferation and accelerate edge cell migration towards the wound center to promote healing (Yan et al., 2005; Chan, 2009). Sexena et al. (2004) believed that this mechanism is in fact the damaged cytoskeleton caused by intermittent negative pressure. This pressure could prompt the release of the second messenger substances and induce the proliferation of repair cells. Under continuous negative pressure, 
vascular endothelial cells show rapid proliferation, which could explain the improvement in wound blood circulation and rapid granulation growth observed over a short period. Labler et al. (2006) found that VAC can regulate the expression of IL-6, IL-8, and VEGF and also play a positive role in angiogenesis. Mouës et al. (2008) found that VAC can inhibit the synthesis of matrix metalloproteinases, thereby inhibiting the degradation of collagen and gelatin, which is more conducive for both granulation formation and collagen deposition.

In the present study, the researchers found that the 7th day after injury is the most optimal time for granulation formation. Vitality of the granulation tissue is highest and full vascularization is observed while skin grafts have the highest rate of survival (Gupta et al., 2012). Thus, VAC was removed 7 days after wound formation and subsequent observation found that by the 15th and 20th days all wounds were scabbed over with no infection. In the seawater-immersed group, $180 \mathrm{mmHg}$ negative pressure was shown to be the best choice owing to rapid wound healing. In the clinic, as soon as conditions allow, subsequent surgical treatment should begin.

Experimental animal models had larger skin scalability and the animal's posture had a greater impact on wound size intuitively; thus, a greater margin of error existed within comparisons of wound sizes, and healing rates were not compared.

\section{VAC affects flora in wounds and reduces the probability of infection}

Infection is an important feature of seawater-immersed wounds. Seawater contains a large number of pathogenic bacteria, including vibrio bacteria and Enterobacteriaceae, especially Vibrionaceae (Ma et al., 2009). The rate of Streptococcus bacterial infection is highest after seawater immersion and is followed by Escherichia coli, Staphylococcus aureus, Staphylococcus epidermidis, Proteus, Pseudomonas aeruginosa, seawater Vibrio and other bacteria (Li et al., 2009; Byard et al., 2011). Initially, the most reported pathogens in seawaterimmersed wounds were Pseudomonas aeruginosa and E. coli as well as Vibrio (Ma et al., 2009). In the clinic, seawater-immersed wound infections are mostly caused by $\mathrm{G}^{-}$bacteria with only a few attributable to $\mathrm{G}^{+}$bacteria (Byard et al., 2011).

Bacterial culture experiments showed that after VAC therapy, the main flora of the experimental group gradually became $\mathrm{G}^{+}$bacteria (Staphylococcus xylosus, Staphylococcus saccharolyticus). These 2 are coagulase-negative staphylococci and are generally considered to be non-pathogenic. G- bacteria included Pseudomonas aeruginosa and Proteus vulgaris, with lower rates of prevalence. Vibrio is considered the most common group in seawater. As it is halophilic and aversive to acid, an ordinary agar culture cannot be utilized and this experiment can therefore not drawn any conclusions regarding this group. Thus, we can infer that VAC affects flora re-distribution, and low flora distribution results in a lower probability of infection.

\section{Under appropriate negative pressure VAC can increase FN synthesis in seawater- immersed wounds}

FN is a polymer protein sugar present in tissue and tissue fluids and can appear very early in wounds. FN is the major promoter of wound healing, thrombosis, migration of repair cell, proliferation, differentiation, and extracellular matrix synthesis. FN participates in the tissue repair and healing processes and significantly accelerates wound surface healing, which can reduce infection rates (Hamill et al., 2012). In chronic wounds, the FN content is low, 
which could be one of the reasons for the delayed healing observed in these types of wounds. After VAC application, the FN content of chronic wounds gradually increases and this is likely to be a favorable factor for the use of VAC in treating chronic wounds (Wood and Molnar, 2011). Thus, evaluation of FN levels provides an estimate regarding wound healing ability. In this study, we observed FN changes in seawater-immersed wounds without negative pressure in order to obtain optimal negative pressure requirements.

The results showed that in wounds without seawater immersion, the FN content was highest with $120 \mathrm{mmHg}$ negative pressure. In seawater immersed wounds with $180 \mathrm{mmHg}$ negative pressure, the FN content was higher but levels were still significantly lower than those of ordinary wounds. Although VAC therapy can promote seawater-immersed wound healing, the treatment time required is longer than that of ordinary wound healing, which is consistent with clinical experience. At the same time, it may be inferred that $180 \mathrm{mmHg}$ negative pressure is superior to conventional $120 \mathrm{mmHg}$ negative pressure for seawater-immersed wounds in the clinic.

In summary, VAC can promote seawater-immersed wound healing, and $180 \mathrm{mmHg}$ negative pressure may be ideal. Seawater-immersed wound healing is a very complex process, and as the number of experimental animals investigated was low $(\mathrm{N}=4)$, the study had limitations. For seawater-immersed wounds, the optimal negative pressure value or range to be applied in VAC therapy requires further investigation.

\section{ACKNOWLEDGMENTS}

China.

Research supported by grants from the Natural Science Research Foundation of

\section{REFERENCES}

Byard RW, Machado AJ and McLelland D (2011). Endobronchial sand casts: an unusual marker of saltwater immersion in a juvenile pygmy sperm whale (Kogia breviceps). Forensic Sci. Med. Pathol. 7: 222-224.

Chan LK (2009). Current thoughts on angiogenesis. J. Wound Care 18: 14-16.

Chen X, Feng X, Xie J, Ruan S, et al. (2013). Application of acellular dermal xenograft in full-thickness skin burns. Exp. Ther. Med. 6: 194-198.

Dahl E (2011). Wound infections on board ship-prevention, pathogens, and treatment. Int. Marit. Health 62: 186-190.

Dong X, Geng Z, Zhao Y, Chen J, et al. (2013). Involvement of mast cell chymase in burn wound healing in hamsters. Exp. Ther. Med. 5: 643-647.

Gabriel A, Shores J, Bernstein B, de Leon J, et al. (2009). A clinical review of infected wound treatment with Vaccum Assisted Closure (V.A.C.) therapy: experience and case series. Int. Wound J. 6: 1-25.

Grauhan O, Navasardyan A, Hofmann M, Müller P, et al. (2013). Prevention of poststernotomy wound infections in obese patients by negative pressure wound therapy. J. Thorac. Cardiovasc. Surg. 145: 1387-1392.

Gupta S (2012). Optimal use of negative pressure wound therapy for skin grafts. Int. Wound J. 9: 40-47.

Hamill KJ, Hopkinson SB, Hoover P, Todorović V, et al. (2012). Fibronectin expression determines skin cell motile behavior. J. Invest. Dermatol. 132: 448-457.

Hu XH, Duan YY, Li Y and Xue ZQ (2010). Early responses of VEGF during acute lung injury induced by seawater immersion after open chest trauma. Respiration 79: 490-496.

Labler L, Mica L, Härter L, Trentz O, et al. (2006). Influnce of VAC-therapy on cytokines and growth factors in traumatic wounds. Zentralbl. Chir. 131: 62-67.

Li H, Yu Y, Luo W, Zeng Y, et al. (2009). Bacterial diversity in surface sediments from the Pacific Arctic Ocean. Extremophiles 13: 233-246.

Li RG, Ren GH, Tan XJ, Yu B, et al. (2013). Free flap transplantation combined with skin grafting and vacuum sealing drainage for repair of circumferential or sub-circumferential soft-tissue wounds of the lower leg. Med. Sci. Monit. 19: 510-517. 
Ma Y, Zeng Y, Jiao N, Shi Y, et al. (2009). Vertical distribution and phylogenetic composition of bacteria in the Eastern Tropical North Pacific Ocean. Microbiol. Res. 164: 624-633.

Masden D, Goldstein J, Endara M, Xu K, et al. (2012). Negative pressure wound therapy for at-risk surgical closures in patients with multiple comorbidities: a prospective randomized controlled study. Ann. Surg. 255: 1043-1047.

Morykwas MJ, Faler BJ, Pearce DJ and Argenta LC (2001). Effects of varying levels of subatmospheric pressure on the rate of granulation tissue formation in experimental wounds in swine. Ann. Plast. Surg. 47: 547-551.

Mouës CM, van Toorenenbergen AW, Heule F, Hop WC, et al. (2008). The role of topical negative pressure in wound repair: expression of biochemical markers in wound fluid during wound healing. Wound Repair Regen. 16: 488-494.

Ogawa R (2012). Treatment of surgical site infection and hypertrophic scars. Kyobu Geka 65: 409-417.

Palm HG, Hauer T, Simon C and Willy C (2011). Vacuum assisted closure of head and neck wounds. HNO 59: 819-830.

Parker P (2012). Re: Application of negative-pressure wound therapy in improvised explosive device-related pelviperineal injuries. J. Trauma Acute Care Surg. 73: 1630.

Scherer LA, Shiver S, Chang M, Meredith JW, et al. (2002). The vacuum assisted closure device: a method of securing skin grafts and improving graft survival. Arch. Surg. 137: 930-934.

Sexena V, Hwang CW, Huang S, Eichbaum Q, et al. (2004). Vacuum-assisted closure: micro deformations of wounds and cell proliferation. Plast. Reconstr. Surg. 114: 1086-1096.

Timmers MS, Le Cessie S, Banwell P and Jukema GN (2005). The effects of varying degrees of pressure delivered by negative-pressure wound therapy on skin perfusion. Ann. Plast. Surg. 55: 665-671.

Witkowski W, Jawien A, Witkiewicz W and Zon B (2009). Initial multi-centre observations upon the effect of a new Topical Negative Pressure device upon patient and clinician experience and the treatment of wounds. Int. Wound J. 6: 167-174.

Wood BC and Molnar JA (2011). Subatmospheric pressure therapy: basic science review. J. Surg. Orthop. Adv. 20: 168-175.

Yan H, Lai XN and Ge HJ (2005). Comparative study on effects of burn-blast combined injury and burn-firearm combined injury complicated with seawater immersion on vascular endothelial cells. Chin. J. Traumatol. 8: 147-150. 